\title{
Identification and Discrimination of Mycobacterium tuberculosis Complex with Traditional and Real-Time PCR in Different Specimens in Iraq
}

DOI: https://doi.org/10.32007/jfacmedbagdad.6231787

\author{
Shaymaa M. Ali* \\ Mohammad A. Al-Faham* \\ Ahmed A.Mankhi**
}

\author{
BSc, $P h D$ \\ PhD \\ MBChB, PhD
}

\section{JFac Med Baghdad 2020; Vol.62, No. 3 Received. Sept. 2020 Accepted Oct. 2020 Published: Nov., 2020}

Background: Tuberculosis (TB) is a major public health issue and a main cause of global morbidity and mortality. TB is the world's ninth leading cause of death despite the numerous treatment strategies for managing the disease.

Objective: To assess the traditional method (direct smear examination and culture) against real-time PCR as pulmonary and extrapulmonary tuberculosis laboratory diagnostic techniques.

Cases and methods: Samples were collected from (612) TB cases, (409) of whom were pulmonary tuberculosis (PTB) and (203) were extrapolmonary tuberculosis (EPTB). The cases were seeking care at the Specialized Chest and Respiratory Disease Center/ National Reference Laboratory for Tuberculosis (NRL) in Baghdad, during the period $1^{\text {st }}$ of May $-1^{\text {st }}$ of October 2019. Direct smear examination, Lowenstein-Jensen culture and Real Time PCR were used to diagnose TB.

Results: Out of 612 samples received, $82(13.4 \%)$ were positive by smear microscopy, while $90(14.7 \%)$ were able to grow on Lowenstein-Jensen $(\mathrm{LJ})$ media. Ninety DNA extracts from the samples which were positive on LJ media and 25 control specimens, were diagnosed with molecular analysis by using real time PCR to determine the species of Mycobacterium tuberculosis complex. The results revealed that the 71 samples (78.9\%) were $M$. tuberculosis, three specimens (3.3\%) were combined M. bovis and M. tuberculosis, and one M. tuberculosis, M. bovis, and M. bovis BCG, while15 (16.7\%) were negative and subsequently excluded from study.

Conclusion: The comparison between molecular diagnostic methods by using Real time PCR with conventional diagnostic methods, provides a new promising technique and is potentially a practical and rapid alternative to the slower traditional pulmonary and EPTB diagnostic culture. The results show $M$. bovis overall contribution on human TB in comparison to M. tuberculosis is minor among PTB and EPTB cases in the sample studied.

Keyword: Pulmonary tuberculosis, extrapulmonary tuberculosis, Real time PCR.

\begin{abstract}
Introduction:
Tuberculosis (TB) is a major public health issue and a main cause of morbidity and mortality in the world. TB is the world's ninth leading cause of death despite the numerous treatment strategies for managing the disease (1). TB is caused by Mycobacterium tuberculosis (MTB) (2). Generally, this bacterium targets the lungs, but the spine, kidney and brain are other exposed organs (3). TB constitutes a major public health issue in Iraq. Iraq is
\end{abstract}

*Corresponding Author: Dept. of Microbiology, College of Medicine, University of Baghdad. shaymaa.ali78@yahoo.com dralfaham55@yahoo.com

**National Reference Laboratory of TB, Ministry of Health, Baghdad. a middle disease-burden country with $\mathrm{TB}$, ranked $108^{\text {th }}$ worldwide and $7^{\text {th }}$ in the Eastern Mediterranean Region among TB burden-size countries (4). There were an estimated 20,000 TB patients in Iraq in 2014 and nearly 4000 died from the disease $(1,5)$. Improvement in TB diagnosis and standardized antiTB therapies is a key to the "end-TB strategy" of the WHO $(6,7)$. Effective TB treatments primarily depend on accurate TB diagnosis (8). In TB diagnosis, molecular methods are being increasingly used (9). The use of real time-PCR in the diagnosis of TB has increased, as it has been shown to be highly specific and sensitive to detect Mycobacterium tuberculosis complex (MTBC) from culture isolates or directly in clinical samples $(10,11$, and 12). 


\section{Cases and Methods:}

Sample Collection and DNA Extraction: Between $1^{\text {st }}$ of May and $1^{\text {st }}$ of October 2019, 612 samples were received from patients attending the Specialized Chest and Respiratory Disease Center/ National Reference Laboratory for Tuberculosis (NRL) in Baghdad. Specimens were separated into two groups: $409(63.4 \%)$ pulmonary TB (PTB) specimens and 203 (36.6\%) extrapulmonary TB (EPTB) specimens. PTB specimens included (285) sputum specimens and (124) Broncho-alveolar lavage specimens. The other specimens that were collected from EPTB cases included pleural fluid (48), urine (42), pericardial fluid (30), ascetic fluid (28), gastric fluid (27), biopsy (10), abscess (7), lymph node aspirate (5), synovial fluid (3), skin swab (2), and Cerebrospinal fluid (CSF) (1). Specimen collection and processing (Decontamination) were carried out according to the laboratory manual guidelines of work (13). ZiehlNeelsen Stain as well as culture on LowensteinJensen media were investigated for the presence of acid fast bacilli. Only L.J medium culture positive of PTB and EPTB samples and specimens from healthy persons were taken to extract DNA with the sonicator method according to National Tuberculosis Control Program (14).

Identification and Discrimination of $M$. tuberculosis complex via Real time PCR
All positive LJ culture of PTB and EPTB and 25 control specimens (people who visited NRL and have negative direct smear examination and culture) have been confirmed with real time PCR by MTB Diff Real-TM kit (Sacace, Italy), and performed according to the kit's protocol.

\section{Statistical analysis}

The significance of difference of different percentages (quantitative data) was tested using Pearson Chi-square test $\left(\chi^{2}\right.$-test) with application of Yate's correction or Fisher Exact test whenever applicable. Statistical significance was considered whenever the $\mathrm{P}$ value was equal or less than 0.05 .

\section{Results:}

Out of (612) specimen received, 82(13.4\%) (55 samples from PTB and 27 from EPTB) were positive by smear microscopy (direct examination), whereas 90(14.7\%) specimens (57 from PTB and 33 from EPTB) were able to cultivate on LJ media. It was noticed that eight negative specimens by direct examination were detected by culture and only (27) EP specimens were diagnosed by ZN stain, while 33 specimens were positive by culture as seen in (table 1).

Table 1: Specimens Distribution According to the Type of TB and the Type of Lab Test

\begin{tabular}{|c|c|c|c|c|c|c|}
\hline 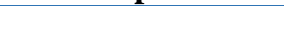 & No of specimen & Direct & & Cultivati & & Positive \\
\hline & & $+\mathrm{ve}$ & $-\mathrm{ve}$ & $+\mathrm{ve}$ & $-\mathrm{ve}$ & culture $\%$ \\
\hline Pulmonary $(\mathrm{n}=409)$ & & & & & & \\
\hline Sputum & 285 & 51 & 234 & 52 & 233 & 57.8 \\
\hline Broncho alveolar lavage & 124 & 4 & 120 & 5 & 119 & 5.6 \\
\hline Extra pulmonary $(n=203)$ & & & & & & \\
\hline Pleural fluid & 48 & 8 & 40 & 11 & 37 & 12.2 \\
\hline Urine & 42 & 3 & 39 & 3 & 39 & 3.3 \\
\hline Pericardial fluid & 30 & 1 & 29 & 1 & 29 & 1.1 \\
\hline Ascetic fluid & 28 & 6 & 22 & 7 & 21 & 7.8 \\
\hline Gastric fluid & 27 & 5 & 22 & 6 & 21 & 6.7 \\
\hline Biopsy & 10 & - & 10 & - & 10 & - \\
\hline Abscess & 7 & 2 & 5 & 3 & 4 & 3.3 \\
\hline Lymph node & 5 & 2 & 3 & 2 & 3 & 2.2 \\
\hline Synovial fluid & 3 & - & 3 & - & 3 & - \\
\hline Skin Swab & 2 & - & 2 & - & 2 & - \\
\hline CSF & 1 & - & 1 & - & 1 & - \\
\hline Total & 612 & $\begin{array}{l}82 \\
(13.4 \%)\end{array}$ & $\begin{array}{l}530 \\
(86.6 \%)\end{array}$ & $\begin{array}{l}90 \\
(14.7 \%)\end{array}$ & $\begin{array}{l}522 \\
(85.3 \%)\end{array}$ & 100 \\
\hline
\end{tabular}

The diagnosis by real time PCR revealed that the greater number of DNA extracted belongs to Mycobacterium genus. As shown in (Figure. 1). The results showed that out of the 90 DNA extracted from (57) PTB and (33) EPTB samples, 71 samples (78.9\%) were $M$. tuberculosis (Figure. 2), three (3.3\%) were combined M. bovis and M. tuberculosis (Figure. 3), and 1for M. bovis, M. tuberculosis, and M. bovis BCG (Figure. 4). Fifteen extracts (16.7\%) (7 samples from PTB and 8 samples from EPTB) were negative and subsequently excluded from study. The results show that $M$. tuberculosis 47 (47/90) represented $(82.5 \%)$ of the PTB samples, and 24 (24/90) $(72.7 \%)$ of the EPTB samples. The two samples of mixed of M. tuberculosis and M. bovis represented $(3.5 \%)$ of the PTB, and one $(3.0 \%)$ of the EPTB, and only one (1/90) $(1.8 \%)$ the mixed of $M$. bovis, M. tuberculosis and M. bovis BCG from the PTB as show in (Table. 2). 


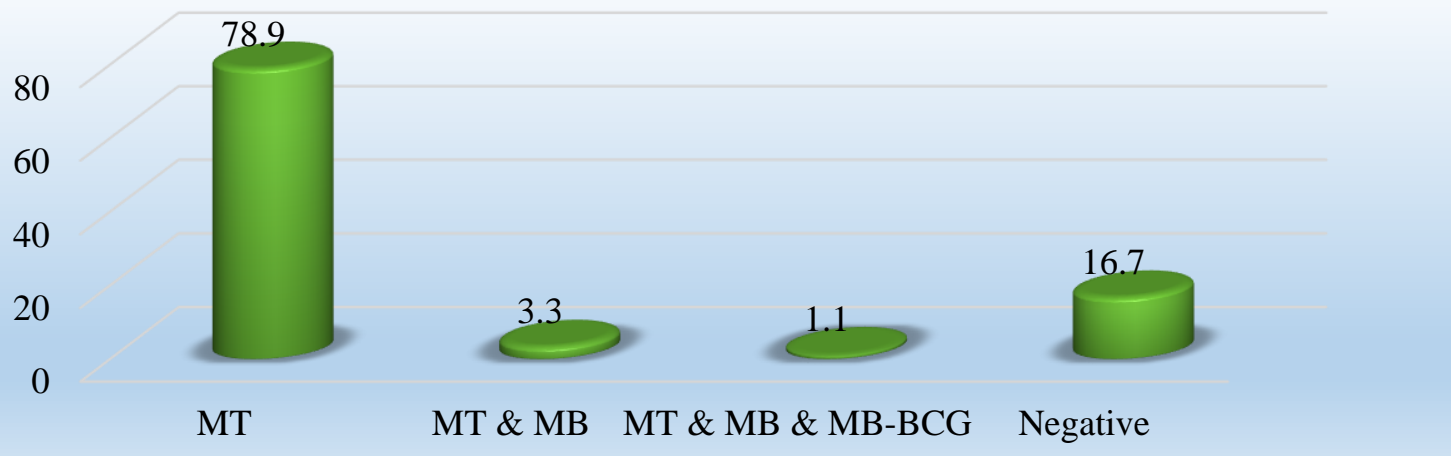

Figure 1: Distribution of 90 DNA Extracted from PTB and EPTB Specimen Detection by Real Time PCR.

Figure 2 shows that for the 13 samples and three of controls (Negative Amplification Control, Positive Amplification Control, and Negative Extraction Control), specific color for each specimen to recognize it from the other specimens. Twelve of these specimens and positive control showed above the threshold line as colored amplification curves (positive result), one specimen and negative control was showed in the colored line under threshold line.
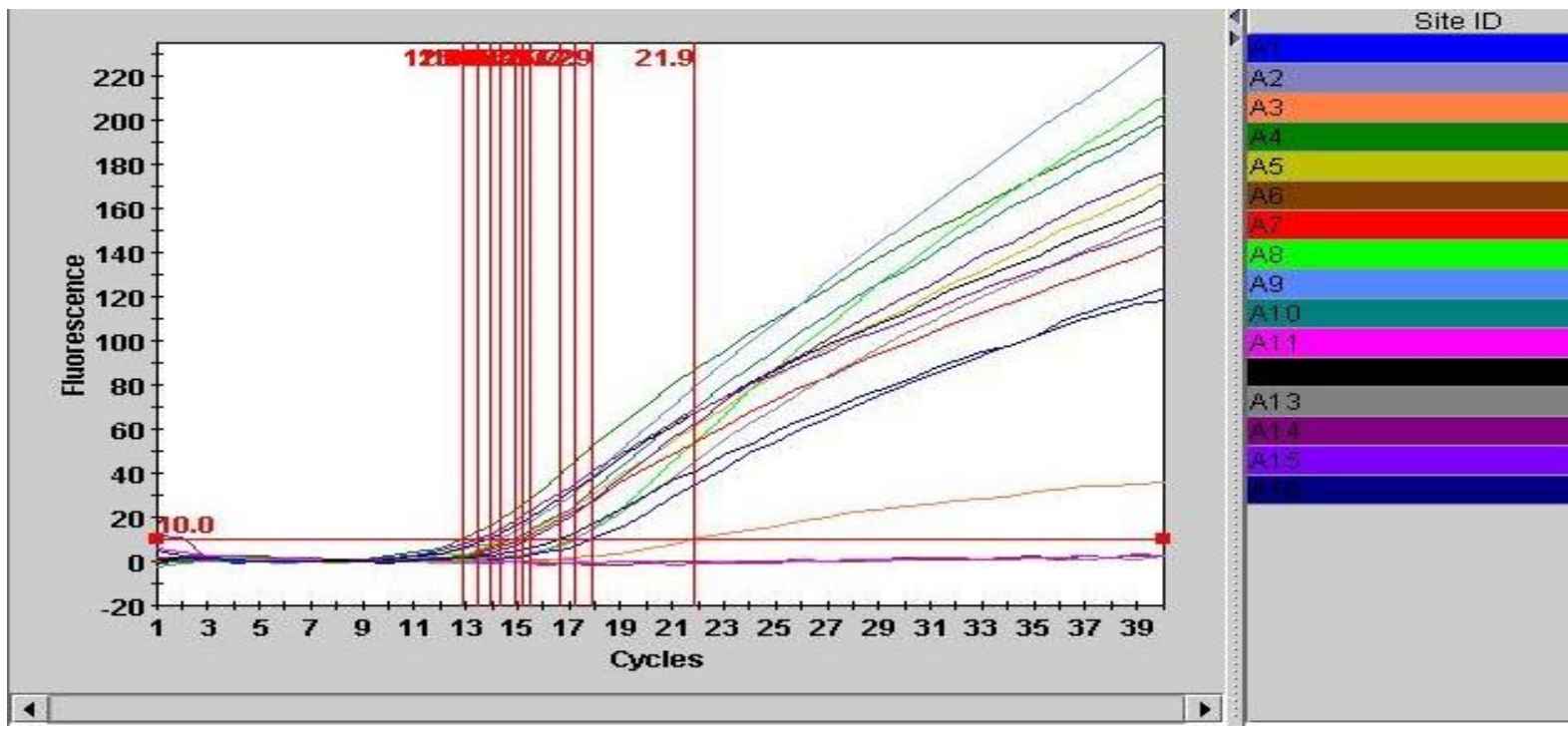

Figure 2: Real Time PCR FAM channel runs to detect $M$. tuberculosis

Figure 3 revealed that for the nine specimens as well as three of controls (Negative Amplification Control, Positive Amplification Control, and Negative Extraction Control), only three colored curves were showed the progress of the amplification for the positive specimens, one of them represent positive control and the other were positive result for M. bovis, and all the specimens appear as a line under the threshold line (negative results) with the negative controls.

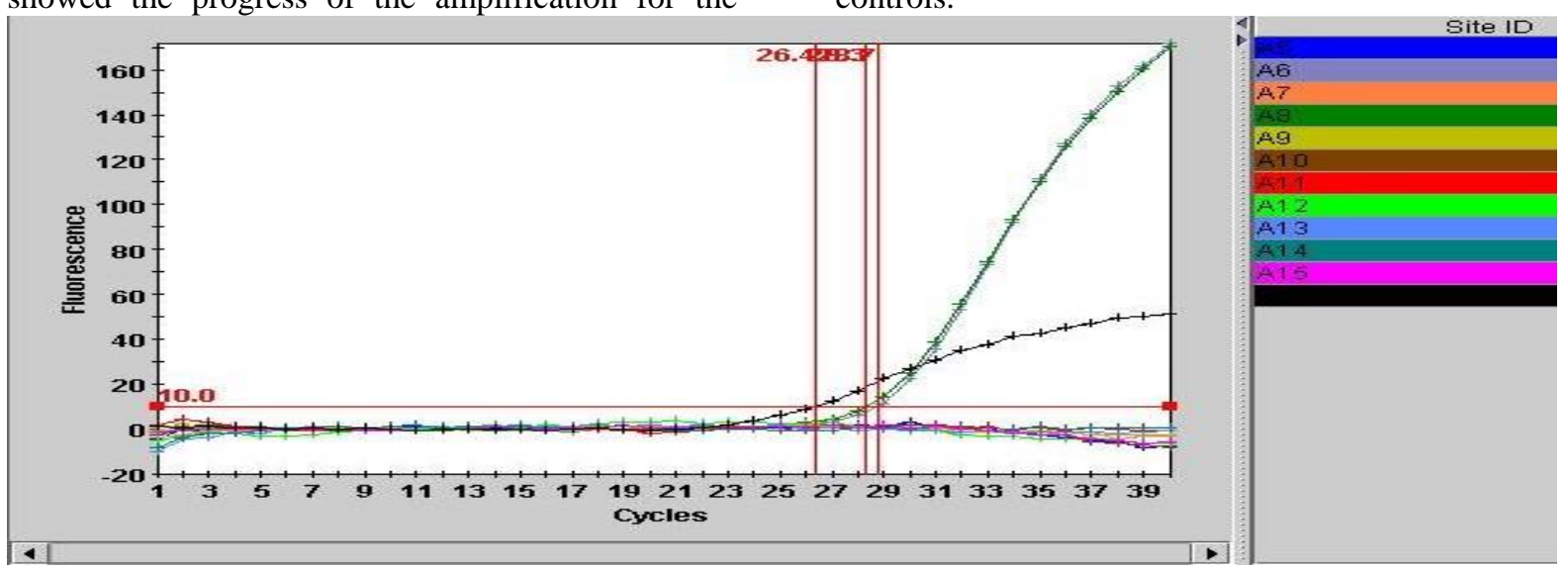

Figure 3: Real Time PCR Cy3 channel runs for detection of $M$. bovis 
Figure 4 shows that for the six specimens for detection of $M$. bovis BCG in addition to three of controls (Negative Amplification Control, Positive Amplification Control, and Extraction Negative Control), five specimens and negative controls were

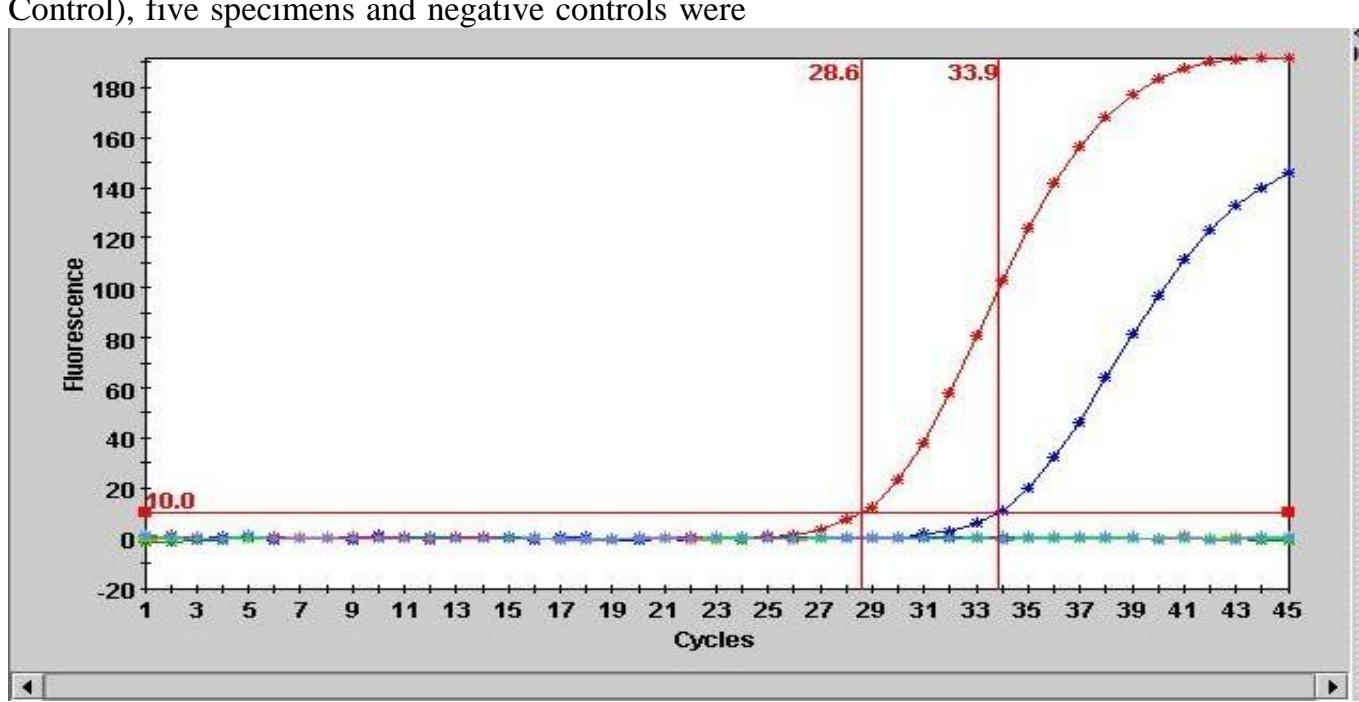

appeared as a line under the threshold line (negative result), the positive control (one curve) and one specimen positive was appeared above the threshold line.

Figure. 4: Real Time PCR TexasRed channel runs for detection of $M$. bovis BCG

Table. 2: Detection of Mycobacterium Species by Real Time PCR.

\begin{tabular}{|c|c|c|c|c|c|c|c|}
\hline \multirow[t]{2}{*}{ Tuberculosis type } & \multicolumn{2}{|l|}{ MT } & \multicolumn{2}{|c|}{ MT \& MB } & $\begin{array}{l}\text { MT \& MB \& MB- } \\
\text { BCG }\end{array}$ & \multicolumn{2}{|l|}{ Negative } \\
\hline & No & $\%$ & No & $\%$ & No $\%$ & No & $\%$ \\
\hline Pulmonary (57) & 47 & 82.5 & 2 & 3.5 & 1.8 & 7 & 12.3 \\
\hline Extra pulmonary (33) & 24 & 72.7 & 1 & 3.0 & - & 8 & 24.2 \\
\hline Total (90) & 71 & 78.9 & 3 & 3.3 & 1.1 & 15 & 16.7 \\
\hline $\mathrm{P}$ value compared to negative & 0.155 & & 0.527 & & 0.302 & - & \\
\hline
\end{tabular}

Table 3 shows the Sensitivity and Specificity of Direct Microscopic Examination (DME) compared to culture Sensitivity $91 \%$, and Specificity $100 \%$, and table 4 shows the Sensitivity and Specificity of PCR compared to culture.

Table 3: Distribution of studied samples according to results of both culture and DME

\begin{tabular}{llll}
\hline & & Culture & \\
\cline { 3 - 4 } & & Positive & Negative \\
\cline { 2 - 4 } & & $\mathrm{N}$ & $\mathrm{N}$ \\
\hline \multirow{2}{*}{ DME } & Positive & 82 & 0 \\
\cline { 2 - 4 } & Negative & 8 & 25 \\
\hline
\end{tabular}

The of Sensitivity and Specificity DME compared to culture

Sensitivity : $91 \%$

Specificity : $100 \%$

Table4: Distribution of studied samples according to results of both culture and PCR

\begin{tabular}{llll}
\hline & & \multicolumn{2}{l}{ Culture } \\
\cline { 3 - 4 } & & Positive & Negative \\
\cline { 3 - 4 } & & $\mathrm{N}$ & $\mathrm{N}$ \\
\hline \multirow{2}{*}{ PCR } & Positive & 75 & 0 \\
\cline { 2 - 4 } & Negative & 15 & 25 \\
\hline
\end{tabular}

The of Sensitivity and Specificity PCR compared to culture

Sensitivity : $\quad 83 \%$

Specificity : $100 \%$

\section{Discussion:}

The present study revealed that similar to many developing countries, the direct smear microscopy method is widely used to diagnose TB in Iraq. The LJ culture medium has been considered the gold standard for TB diagnosis in developing countries (15). Although the microscopic examination and culture remain the cornerstone of the TB diagnosis, there are several drawbacks to these conventional bacteriological procedures, due to the long time need for the culture results, and the low sensitivity of the $\mathrm{ZN}$ smearing particularly with small numbers of the organisms in clinical specimens (16). Positivity of cultures in this study was high compared to microscopy of AFB smears. Approximately 5000$10000 \mathrm{AFB} / \mathrm{ml}$ of specimens is required in order to produce positive results with AFB smear microscopy, while the LJ medium culture advantage is that it is very specific with a sensitivity of $80-85 \%$ and only 10 bacteria per milliliter of specimens can be detected $(17,18)$. Our results confirmed the limited sensitivity of the AFB smear although it is a specific test, as well 
as the culture on LJ medium is being the gold standard with higher sensitivity. The detection rate is always $30-50 \%$ higher compared to microscopy (19). There are different indications that $\mathrm{ZN}$ stain sensitivity for sputum specimens does not exceed 60-70\% compared to sputum culture specimens (20), and $\mathrm{ZN}$ stain sensitivity for EP samples ranged from $0 \%$ to $75 \%$ (21). In this study these results were clear, only $27 \mathrm{EP}$ specimens were diagnosed with $\mathrm{ZN}$ stain, while 33 specimens were diagnosed with solid culture. Diagnosis of EPTB, in particular, it is difficult because of the pauci-bacillary nature of the disease, the distribution of the sample for different diagnostic tests resulting in a non-uniform distribution of microorganisms, the difficulty in collecting sufficient specimens, the variable clinical presentation, and the need for invasive procedures to secure an appropriate sample (22), lack of laboratory facilities in the resource-limited settings and the lack of appropriate specimens processing methodology generally applicable to all forms of extra-pulmonary samples (23). All these limitations lead to the poor establishment of an EPTB diagnosis through bacteriological techniques (24). Our results were in discordance with those reported by Abbadi et al in Egypt (25) who stated that among the (45) $M$. tuberculosis complex isolates from sputum specimens, (44) were identified as M. tuberculosis and only one as $M$. bovis. The results or our study also disagree with those of Ali (26) in Iraq which revealed the absence of $M$. bovis, and with the study conducted by Ahmed in 2018 that showed M. tuberculosis as the only species from $M$. tuberculosis complex circulating in Iraqi patients (27). The present finding is in disagreement with study by Al-Hajoj et al (28) who found only M. tuberculosis isolates with no other species in EPTB specimen, and with results by Siala et al (29) in south Tunisia who reported the occurrence of the following species: (20) $M$. tuberculosis, (75)M. bovis, (2) M. bovis BCG from total of 97 EPTB specimens. Our results on species identification by Real-time PCR in different specimen of pulmonary and EPTB are in disagreement with a study in Ethiopia which reported that out of 964 isolates from pulmonary and ЕРTB, most of those isolates were classified as $M$. tuberculosis, with only four $(0.4 \%) M$. bovis isolates obtained from cases of PTB (30). They were also incompatible with Torres-Gonzalez et al (31) study that found from EP disease $41.6 \%$ of cases was M. bovis, and $30.1 \% \mathrm{M}$. tuberculosis, while $36 \%$ of $\mathrm{M}$. bovis was observed in pulmonary disease, compared to $52.6 \%$ of $\mathrm{M}$. tuberculosis.

In the present study, $15(16.7 \%)$ samples were found to be positive by cultivation method but was negative by PCR, this may attributed to non-tuberculous mycobacterial strains in the samples, or the presence of PCR inhibitors in various clinical specimens (32), low bacterial load as previous studies have confirmed (33), and unequal distribution of AFB in these samples (34). Negative PCR results may be attributable to the nil or very low number of
Mycobacterium copies in the sample (35). The study findings are similar to the study results by Ahmed (27), who found that $6(3.8 \%)$ isolates were negative results and identified as non- tuberculous mycobacteria (NTM).

\section{Conclusion:}

The comparison between molecular diagnostic methods by using Real time PCR with conventional diagnostic methods provides a new promising technique and is potentially a practical and rapid alternative to the slower traditional pulmonary and EPTB diagnostic culture. Mycobacterium tuberculosis plays a major role in producing pulmonary and EPTB in Baghdad compared to Mycobacterium bovis.

\section{Author's contributions:}

Shaymaa M. Ali: PhD student

Mohammad A. Al-Faham: first supervisor

Ahmed A.Mankhi: second supervisor

\section{Reference:}

1-World Health Organization. Global tuberculosis report 2018: WHO/CDS/TB/ 2018.25. Geneva: WHO; 2018.

2-WHO. (2015).Tuberculosis Fact sheet N104. October 2015. Retrieved 11 February 2016.

3-World Health Organization (WHO). Global tuberculosis report 2016

2017.

Available

from: www.who.int/iris/handle/10665/250441.

4-Durib AK. Prevalence of tuberculosis in Baghdad, Iraq 2012. Int J Sci Res Publ. 2018;8(2):565-70.

5-Eastern Mediterranean Regional Office (EMRO, 2019), World Health Organization. Iraq tuberculosis http://www.emro.who.int/irq/programmes/tuberculos is.html. Accessed 1 Sept 2019

6-Uplekar M, Weil D, Lonnroth K, Jaramillo E, Lienhardt C, Dias H M, et al (2015). WHO's new end TB strategy. The Lancet, 385(9979), 1799-1801.

7-Schito M, Maeurer M, Kim P, Hanna D, \& Zumla A. (2015). Translating the tuberculosis research agenda: much accomplished, but much more to be done. Clinical Infectious Diseases, 61(suppl_3), S95S101.

8-Ryu YJ. (2015). Diagnosis of pulmonary tuberculosis: recent advances and diagnostic algorithms. Tuberculosis and respiratory diseases, 78(2), 64-71.

9-Nakajima C, Rahim Z, Fukushima Y, Sugawara I, van der Zanden A, Tamaru A, et al. 2010. Identification of Mycobacterium tuberculosis clinical isolates in Bangladesh by a species distinguishable multiplex PCR. BMC Infectious Diseases. 10:118.

10- Cleary TJ, Roudel G, Casillas O, \& Miller N. (2003). Rapid and specific detection of Mycobacterium tuberculosis by using the Smart Cycler instrument and a specific fluorogenic probe. $J$ Clin Microbiol 41, 4783-4786.

11-Armand S, Vanhuls P, Delcroix G, Courcol R. \& Lemai tre N. (2011). Comparison of the Xpert 
$M T B / R I F$ test with an IS6110- TaqMan real-time PCR assay for direct detection of Mycobacterium tuberculosis in respiratory and nonrespiratory specimens. J Clin Microbiol 49, 1772-1776.

12-Lira LA, Santos FC, Carvalho MS, Montenegro $R A$, Lima JF, Schindler HC, et al. (2013). Evaluation of a IS6110-Taqman real-time PCR assay to detect Mycobacterium tuberculosis in sputum samples of patients with pulmonary TB. J Appl Microbiol 114, 1103-1108.

13-Mankhi AA. (2009). Manual of Laboratory guide line in the national reference laboratory in Iraq (2nd Edition). Ministry of Health. Chest and respiratory Diseases center in collaboration with WHO. Baghdad. Iraq.

14-National Tuberculosis Control Program (2015).National Reference Laboratory in Iraq, Laboratory Manual guide line (Third Edition) Ministry of Health. Chest and respiratory Diseases center in collaboration with WHO. Baghdad. Iraq. 15-Shoukrie A, Alameen A, Shaban D, Alamari W, Aboguttaia N, Askar N, et al. The yield of sputum smear direct microscopy using Ziehl Neelsen stain in comparision with Lowenstein Jensen culture on the diagnosis of pulmonary tuberculosis in Tripoli libya. Mycobact Dis, an open access journal, 2018; 8(1)1000256:1-4.

16-Negi, SS, Khan SFB, Gupta S, Pasha ST, Kare S, and LalS. (2005). Comparison of the Conventional Diagnostic Modalities, BACTEC Culture and Polymerase Chain Reaction Test for Diagnosis of Tuberculosis. Indian J. Med. Microbiol. 23(1): 29-33. 17-Parsons L, Somoskövi A, Gutierrez C, Lee E, Paramasivan C, Abimiku A, et al. (2011). Laboratory Diagnosis of Tuberculosis in Resource-Poor Countries: Challenges and Opportunities. Clin. Microbiol. Rev. 24 (2): 314-350.

18-Ananthnarayan and Paniker's Textbook of Microbiology, 10th Edition (2019) ch. no. 38 mycobacterium I: M. tuberculosis Page No. 351 to 365 Editor Reba Kanungo, Hyderabad, India, Universities Press (India) Private limited 2013, 2017. 19-WHO (2015). Implementing TB diagnostics: policy framework. Implementing tuberculosis diagnostics: policy framework. World Health Organization;

http://apps.who.int/iris/handle/10665/162712.

Accessed 1 Oct 2018.

20-Levy H, Feldman C, Sacho H, van der Meulen H, Kallenbach J, and Koornhof H. (1989). A reevaluation of sputum microscopy and culture in the diagnosis of pulmonary tuberculosis. Chest. 95(6): 1193-1197.

21-Kamboj SS, Goel MM, and Tandon P. (1994). Correlation study of histopathology and bacteriology in patients of tubercular lymphadenitis. Ind. J. Chest. Dis. Allied Sci. 36(4):187-91.

22-Purohit M, and Mustafa T. Laboratory diagnosis of extra-pulmonary tuberculosis (EPTB) in resourceconstrained setting: State of the art, challenges and the need. J Clin Diagnostic Res. 2015;9 (4):1-6.
23-Manjunath N, Shankar P, Rajan L, Bhargava A, Saluja SS. Evaluation of a polymerase chain reaction for the diagnosis of tuberculosis. Tubercle. 1991; 72(1):21-7.

24-Maurya AK, Kant S, Nag VL, Kushwaha RADT. Trends of anti-tuberculosis drug resistance pattern in new cases and previously treated cases of extrapulmonary tuberculosis cases in referral hospitals in northern India. J Postgr Med. 2012;58(3):185-9.

25-Abbadi S, El-Hadidy G, Gomaa N, and Cooksey R. (2009). Strain differentiation of Mycobacterium tuberculosis complex isolated from sputum of pulmonary tuberculosis patients. International Journal of Infectious Diseases. 13: 236-242.

26-Ali R. (2013). Molecular study and Genotyping of Mycobacterium tuberculosis complex isolated in Respiratory Center in Baghdad. Ph.D. Thesis. Institute of Genetic Engineering and Biotechnology for Postgraduate Studies, University of Baghdad.

27-Ahmed ST. (2018). Molecular Investigation and Genotyping of Pulmonary Mycobacterium tuberculosis Strains in Iraq. PhD Thesis, College of Science for Women, Baghdad University, Iraq, Pp. 1171.

28-Al-Hajoj S, Shoukri M, Memish Z, AlHakeem R, AlRabiah F, \& Varghese B. (2015). Exploring the sociodemographic and clinical features of extrapulmonary tuberculosis in Saudi Arabia. PLoS One, 10(2), e0101667.

29-Siala M, Smaoui S, Taktak W, Hachicha S, Ghorbel A, Marouane C, et al. (2017). First-time detection and identification of the Mycobacterium tuberculosis Complex members in extrapulmonary tuberculosis clinical samples in south Tunisia by a single tube tetraplex real-time PCR assay. PLOS Neglected Tropical Diseases, 11(5), e0005572.

30-Firdessa R, Berg S, Hailu E, Schelling E, Gumi B, Erenso G, et al. (2013). Mycobacterial lineages causing pulmonary and extrapulmonary tuberculosis, Ethiopia. Emerging infectious diseases, 19(3), 460.

31-Torres-Gonzalez P, Cervera-Hernandez ME, Martinez-Gamboa A, Garcia-Garcia L, Cruz-Hervert LP, Bobadilla-del Valle M, et al. (2016). Human tuberculosis caused by Mycobacterium bovis: a retrospective comparison with Mycobacterium tuberculosis in a Mexican tertiary care centre, 2000 2015. BMC infectious diseases, 16(1), 657.

32-Kabir S, Uddin MKM, Chisti MJ, Fannana T, Haque ME, Uddin MR, et al. (2018). Role of PCR method using IS6110 primer in detecting Mycobacterium tuberculosis among the clinically diagnosed childhood tuberculosis patients at an urban hospital in Dhaka, Bangladesh. International Journal of Infectious Diseases, 68, 108-114.

33-Bechnoosh A, Lieberman JM, Duke MB, Stutman HR. Comparison of Quantitative polymerase chain reaction, therapy for pulmonary tuberculosis. Diag Microb Infect Dis 1997;29:73-79.

34-Iqbal S, Ahmed R, \& Mumtaz A. (2011). Importance of polymerase chain reaction in diagnosis of pulmonary and extra-pulmonary 
tuberculosis. Journal of Ayub Medical College Abbottabad, 23(1), 73-76.

35- Ramana BV, Srikar A, Prakash P, Chaudhury A. (2019). Diagnosis of Extrapulmonary Tuberculosis by Real Time PCR and Comparison with
Conventional Diagnostic Methods International Journal of Scientific Research, Volume-8 | Issue-10| October - 2019| PRINT ISSN No. 2277 - 8179| doi: 10.36106/ijsr.

\title{
تثخيص وتفريث بكتريا التدرن من مختلف النماذج باستخدام الطرق التقليدية وتفاعل البوليميراز المتسلسل اللحظي في العراق
}

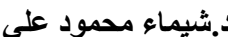

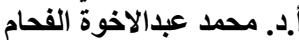

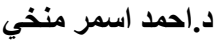

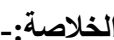

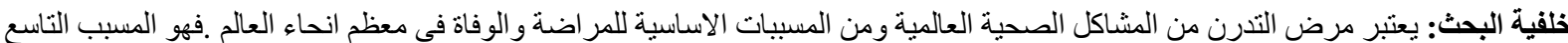

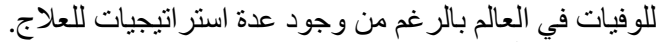

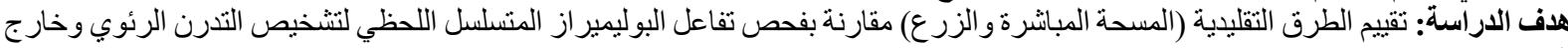
الرئوي.

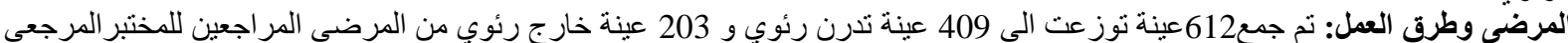

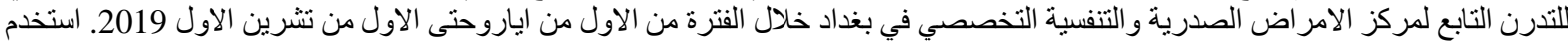

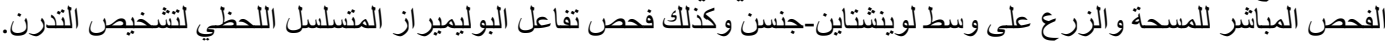

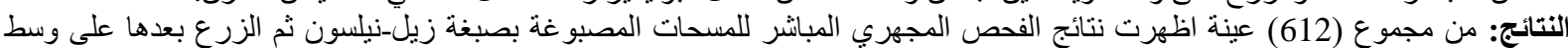

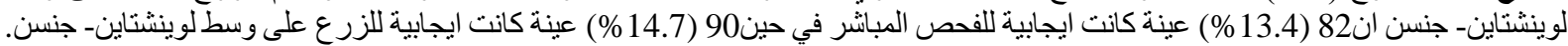

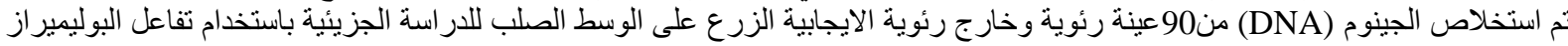

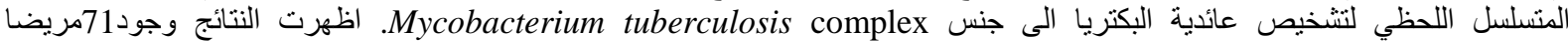

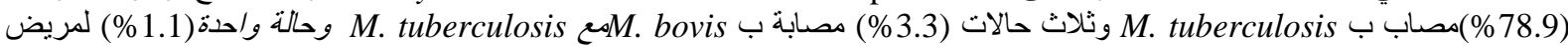

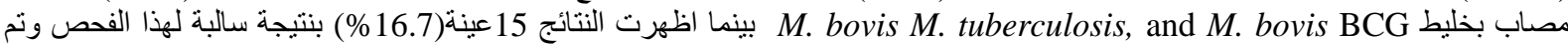
استبعادها من هذه الدر اسة.

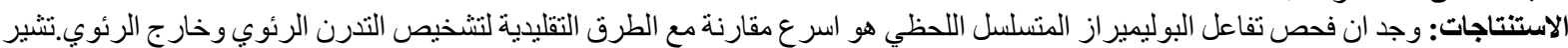

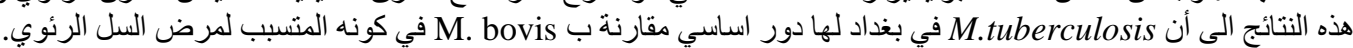

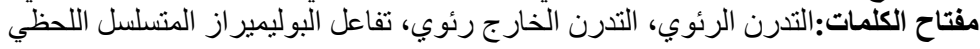

